流机の可視化 Vol.7 No.26 (1987年7月)

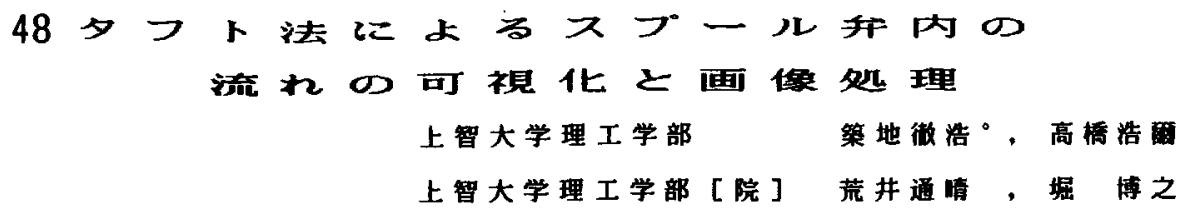

Flow Visualization in the Spool Valve by Tuft Method

Tetsuhiro TSUKIJI , Koji TAKAHASHI
Michiharu ARAI and Hiroyuki HORI

\begin{abstract}
In designing spool valves which are widely used in hydraulic power applications, one of the most important problems is to estimate and reduce the axial force acting on the spool of the valve. This axial force can easily be estimated from. momentum theory if the behavior of the jet issuing from the metering orifice of the spool valve is expected.

In the present paper, a three-dimensional model of the spool valve has been designed to observe the flow near the metering orifice. This model is made of transparent acrylic resins. The jet issuing from the metering orifice is visualized by a tuft method. The images of flow fields recorded by CCD camera are fed into a microcomputer and an digital image processing is employed to investigate the behavior of the jet.
\end{abstract}

\title{
1. 㹥めに
}

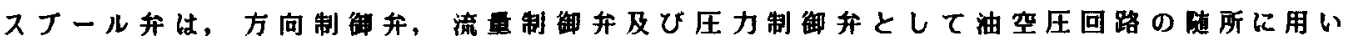

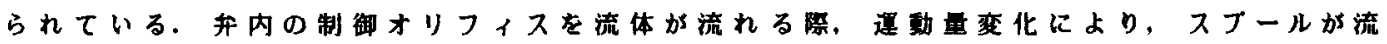

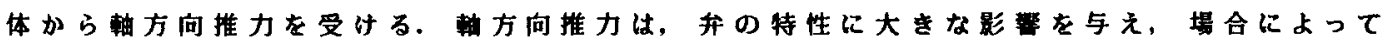

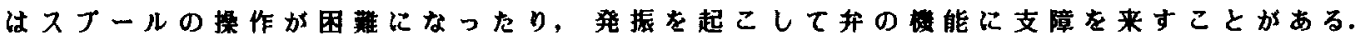
したがって，軸方向推力を見種り镊娍することは，弁の設計上基本的閣題の一つでる。

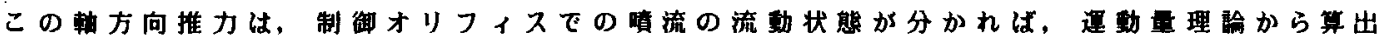
されるので(1)，䖝り付近の流れを解明することは重要なことでる.

そこで, 本研究では実祭の弁に即したスフール弁の三次元モテルをアクリル樹を用い て作し，タフト法により制オリフィスからの略流の可視化実卧を行った。さらに，C

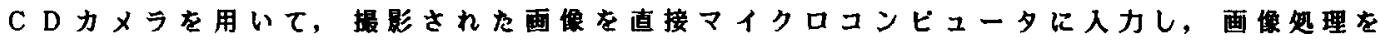
施し，大同的な嘖流の流到形㮩の解明を試みた。

\section{2. 可視化実路}

供試弁の形状を图1に示す。供試弁は入口出口ボートをそれぞーつすっつ有する全周较

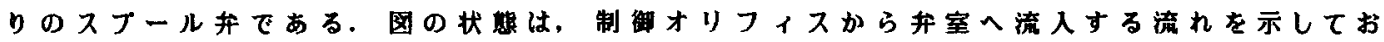
り，流れの方向を逆転させることにより弁室から流出する流れも作ることかてきる.本研 究で屾雨方の場合について行った。供試弁はそのまま水槽の中に人れられ，その中に水を

* Department of Mechanical Engineering, Sophia University, 7-1, Kioicho, Chiyoda-ku, Tokyo, 102 Japan 
入れることにより光の屈折による制槹部の像の歪を少なくしている. 图中の記号で, Lは 弁開度を表し，aは弁室深さと呼ふことにする。

タフトを取り付けた位置を图 2 に示す,これは图1のA方向からランドを見た图である。 图に示すように弁室盘 のランドの制面に

22 . 5 ・の等角度間 隔に16 本のタフトを 取り付けた。流入ボー ト方向にあるタフトの 番号を0とし, 時計方 向に1 8 までの番号 を各タフトに割付け, 同様に半時㖕方向に

- 1 - 7 までの番号

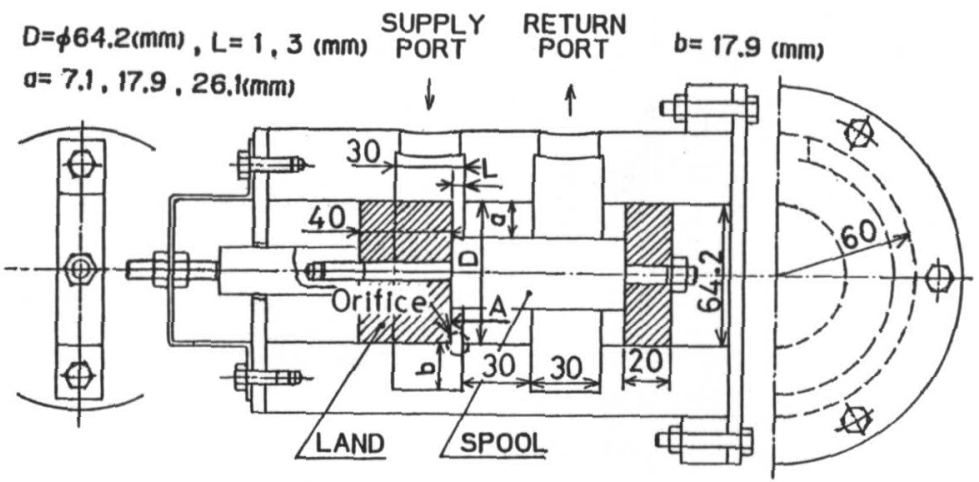

Fig.1 Spool valve model

を付的た。 タフトは7〜1 $1 \mathrm{~mm}$ の長さの綃系を用いた。レイノルズ数

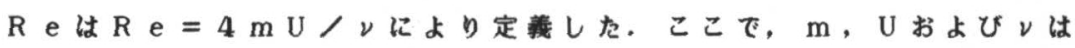
それぞれ流体平均深さ, 较り部に拀什る平均流速および流体の動粘度 である.撮影された代表的な可視化写真を图 3 に示す。（a）および （b）は輤方向および径方向からそれぞれ撮影された写真である。撮 影条件は, 霜出時間 $1 / 30$ 梦, 较り F 8, A S A 100 である. レ

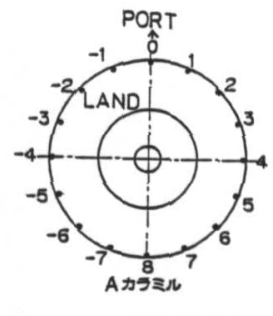

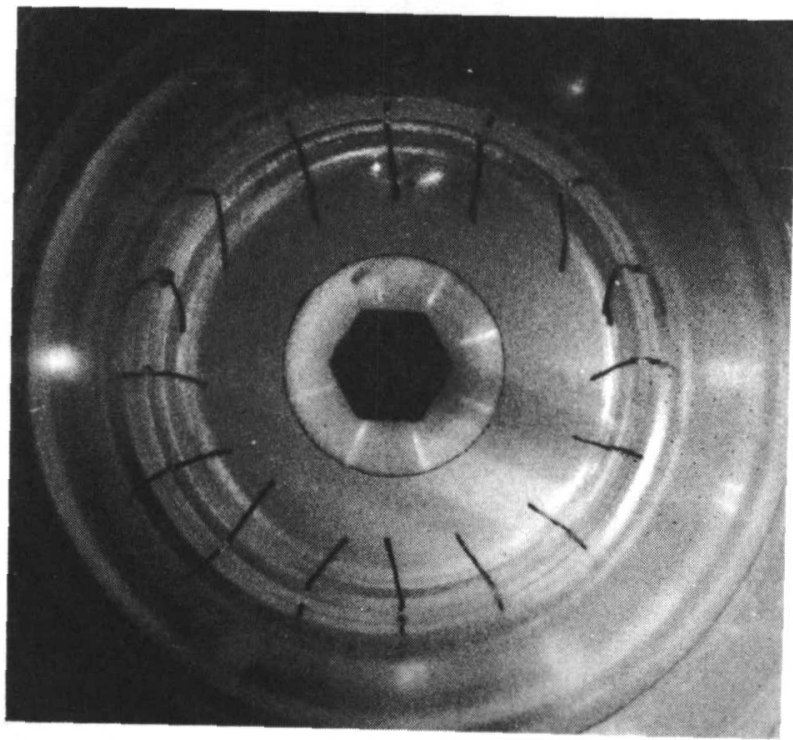

(a)

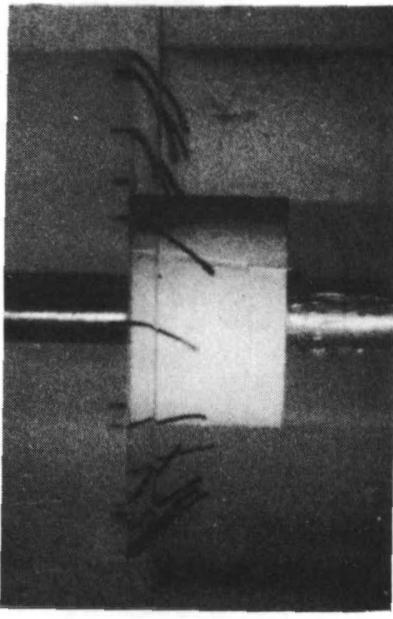

(b)

Fig. 3 Photographs ( $L=3 \mathrm{~mm}, a=17.9 \mathrm{~mm}, R e=516, F 8,1 / 30$, ASA 100$)$ 
イノルス数は比的低いので流れは安定しておりタフトの振れ角は小さい。

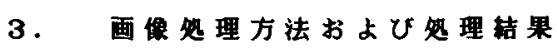

C C Dカメラにより1/30秒でサンフリングした画偠をlage processor に入力する.

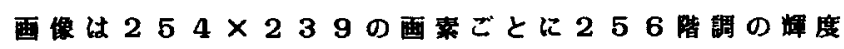
レベルで鿁される. 2 . 325 秒おきに99回のサ ンブリンクを行って加算题理した。しきい值を透定し 二值化を行いウィンドーカーソルを用いてノイスを消 去する.代表的な处理結果を图4に示す。これ约弁 室へ流入する贾合の流れを示しており，タフトの振れ の样子か分かる。图4などの二值化された唃方向か らの画像から，以下に述べる方法によって，タフトの

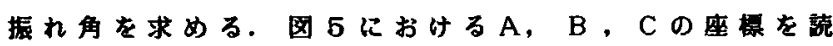

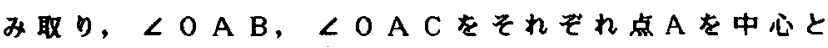
して，半時部方向を正として角度を求めた。因 6 は,

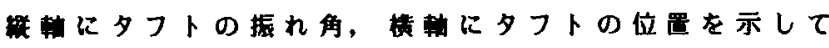
おり，○は噴流がランドに付着していることを示し，

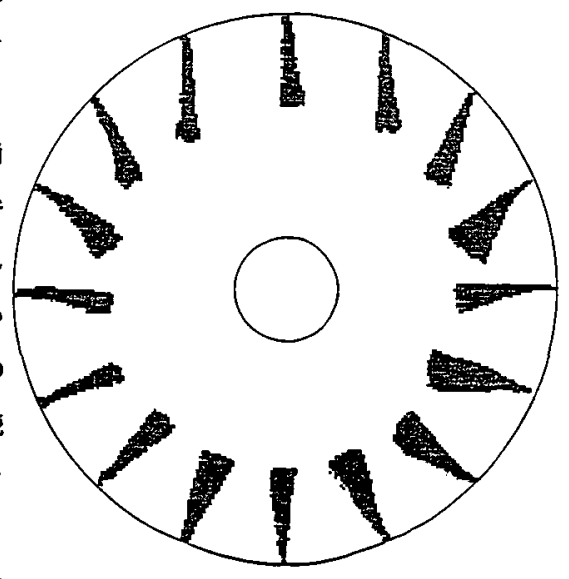

Fig.4 Digital realization $(\mathrm{L}=1 \mathrm{~mm}, \mathrm{a}=26.1 \mathrm{~mm}, \mathrm{Re}=1649)$

・ 屾非付着を示している。これは弁室へ流入する場合

である.タフト位器 $\pm 1 \sim \pm 4$ 付近は周方向の速度の影整を受

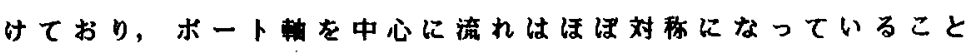

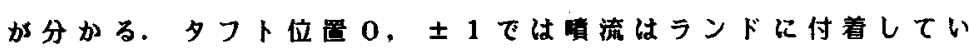
る.图 7 は，图6の場合より，弁室深さを変化させた場合であ ろ. 图6，7より弁室深さa加浅い方がフトの层れ角が大き く，タフトは付着していないことが分かる，付着に関する弁室

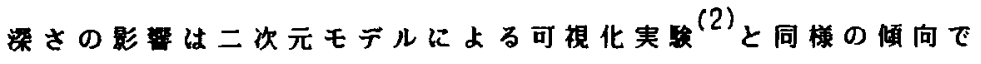

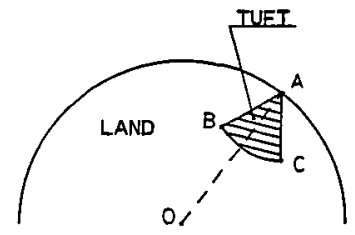

Fig. 5 Measuiement of a deviation angle ある. 图 8 は, 并䦕度 $\mathrm{L}=1 \mathrm{~mm}$, 弁室深さ $\mathrm{a}=26.1 \mathrm{~m}$ の場

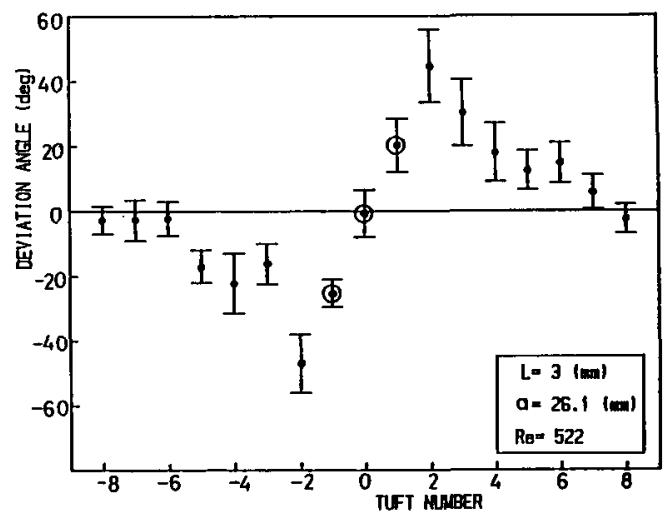

Fig.6 Deviation angle for different tuft positions

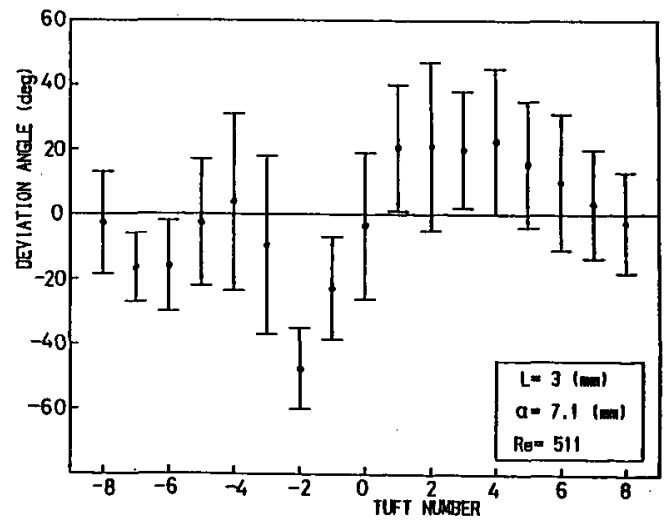

Fig. 7 Effects of a on deviation angle 

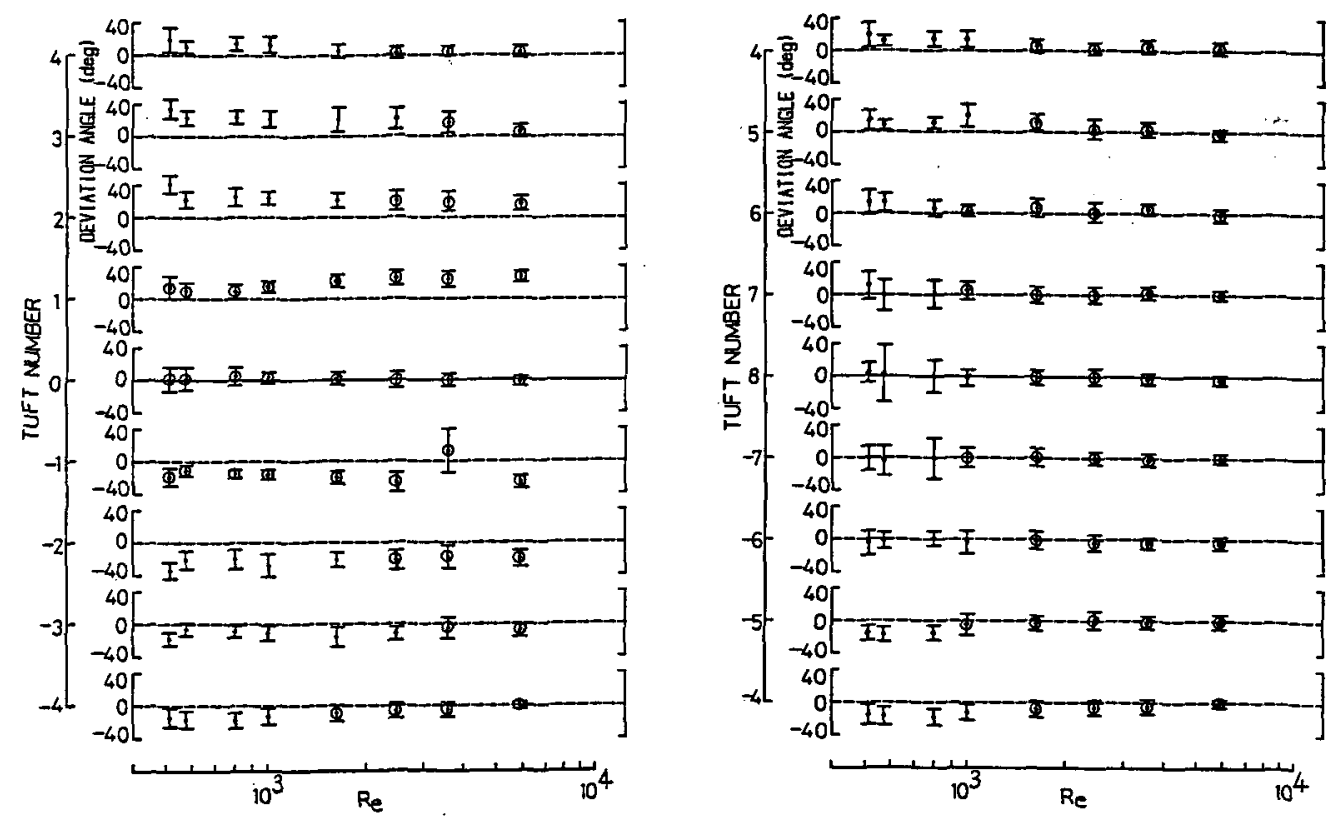

Fig. 8 Variations of deviation angle with $R e$

合のレイノルズ数の变化に対する各タフトの振れ角の様子を示している。レイノルス数が

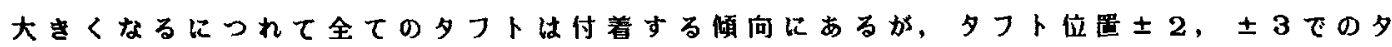
フトは付着しにくいささらに，タフト番号士1以外ではレイノルズ数の增加とともに周方

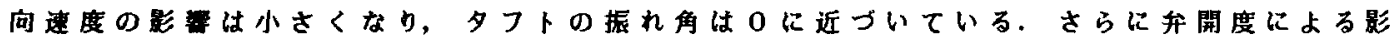

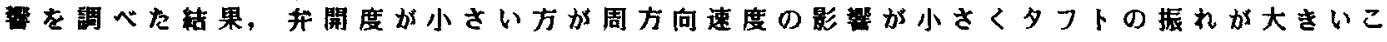
とが分かった。

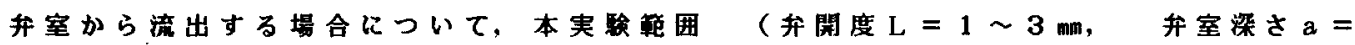
7. $1 \sim 26.1 \mathrm{~mm}$, レイノルス数 $\mathrm{R} \mathrm{e}=500 \sim 2500$ ) で, 全ての位㫣のタフトは 付举した。并室へ流入する場合と同様にレイノルズ数が大きくなると周方向速度の影䈉汕

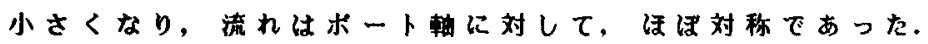

4.おわりに

本研究では，実際のスフール弁に即した三次元モテルをアクリル樹脂で作り，タフト法 により制御オリフィスからの啫流の可視化实駼を行い，画像处理落を用いてタフトの振 れ角などを定量的に求めた。その結果, レイノルズ数, 弁室梁さなどのハラメー夕が啨流 の大局的挙動に及ほすす影辢を明らかにした。

最後に, 上智大学理工学部機械工学科流体工学研究室の諸氏に感謝の意を表す。

\section{参考文神}

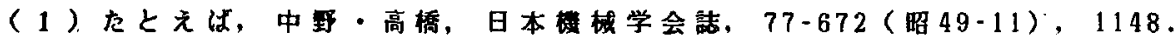

（2）福島，油压と空気压，5-3(昭 49-7)，127. 